\title{
Family Caregiver's Adjustment for Their Children with Hearing Impairment
}

\author{
Entessar Ahmed Ali*, Seham Guirguis Ragheb**, Soha Mohamed Hamada***, and \\ Nadia Ibrahim** \\ * Children Cancer Hospital Egypt 57357 \\ ** Community Health Nursing, Faculty of Nursing, Ain Shams University \\ *** Audio vestibular Medicine, Hearing and Speech Institute, at Embaba district
}

\begin{abstract}
Background: Hearing loss affects not only the individual, the entire family and society generally. Infants and children require access to detailed sound for auditory learning. Aim: Recognize family's adjustment for their children with hearing impairment. Design: A descriptive analytical research was used. Setting: "Hearing and Speech Institute" at Embaba district. Sample: Convenient sample of (60) child with hearing impairment. Tools for data collection: Data were collected through the following tools "Family's adjustment questionnaire for children with hearing impairment" it consists of fourth parts; Socio-demographic characteristics for family caregiver, Family caregivers' knowledge, reported practices, and An adjustment scale to assess family caregivers' adjustment toward caring of the children with hearing impairment. Results: the study revealed that, most of family caregivers are female and mothers as a caregiver, and have acceptable score level of knowledge, and most of practices (98.3\%) have done. Moreover, most of practices (98.3\%) have done by caregivers. Besides, the majority of caregivers (98.3\%) have high adjustment. Conclusion: there was negative significant correlation between knowledge and practice; there was positive non-significant correlation between knowledge and adjustment, and there was almost no correlation between practice and adjustment. There was non-significant correlation between education level for caregiver and practice, adjustment, and knowledge. Recommendation: Continuous supervision for maternal and neonatal care by the Ministry of Health and Population, and Periodic Hearing Screening for Early Identification should be done for children before 6 months of age.
\end{abstract}

Key words: Hearing impairment, family caregiver's, adjustment.

\section{Introduction}

The senses have a major impact on the life of all organisms. They are responsible for the perception of the world around us; they help shape our experiences and affect our ability to interact with the surroundings. Generally, life is richer with sharp and well-functioning senses, and their function is often taken for granted (Zeng and Djalilian, 2010)

Hearing loss is the most common sensory defect in humans. According to the World Health Organization, over 270 million people worldwide have moderate to profound hearing loss, with one fourth of 
these cases beginning in childhood. In most cases, hearing loss is a multifactorial disorder caused by both genetic and environmental factors (Kim, et.al, 2010).

Deafness is not simply the deprivation of sound. It is rather deprivation of language. Even this view is considered to be narrow at present. It is now believed that hearing impairments of a very mild and episodic kind do much more than interfere with what children can hear of the language around them. Hearing impairment affects not only the language development of the child but also many aspects of the child's social, emotional and educational development. When there is a more sever sensorineural loss, early social interactions between the parents and the child are disrupted. These early stages are crucial to later language development (Reddy, 2010).

Permanent childhood hearing impairment is best identified through newborn hearing screening programmes. Early identification and effective management of hearing loss optimizes outcomes. By making sound audible from the first months of life through hearing aids, it is possible to harness auditory plasticity and maximize lifetime auditory potential. For infants with profound hearing loss or auditory neuropathy the option of cochlear implantation may give improved hearing for speech, typically at around 12 months of age. The onus of responsibility for using hearing aids and providing a suitable sound environment for the child falls on the parents (Josephine, et.al, 2017).

Possible causes of congenital hearing loss such as infections during pregnancy (German measles, toxoplasmosis and cytomegalovirus), ototoxic medication used during pregnancy, and disorder of the brain or nervous system. Possible causes of acquired hearing loss such as untreated middle-ear infections, perforation of the eardrum, and serious injury to the head (Palo Alto Medical Foundation, 2015).

Family caregiver is defined as "a person who cares for relatives and loved ones who are frail, elderly, or who have a physical or mental disability" (Ronda, \& Shirley, 2013).

Adjustment to hearing loss counseling refers to the support provided by audiologists to families as they learn of their child's hearing loss and attempt to recognize, acknowledge, and understand the realities of having a child with hearing loss (ASHA, 2016).

The community health nurse may assess for the presence of a hearing impairment and refer the client for audio logical evaluation and treatment. The nurse provides support, counseling, and advice on locating affordable resources (e.g., funding for a hearing aid that is not covered by Medicare) and securing appropriate intervention (Frances, \& Claudia, 2013).

\section{Significance of the Study}

Hearing loss affects not only the individual but also the entire family and society generally. Over $5 \%$ of the world's population - 360 million people - has disabling hearing loss (328 million adults and 32 million children). Disabling hearing loss refers to hearing loss greater than 40 decibels $(\mathrm{dB})$ in the better hearing ear in adults and a hearing loss greater than $30 \mathrm{~dB}$ in the better hearing ear in children. The majority of people with disabling hearing loss live in low- and middle-income countries. $32(9 \%)$ millions of these are children. The prevalence of disabling hearing loss in children is greatest in South Asia, Asia Pacific and Sub-Saharan Africa (WHO, 2015). 
The aim of the study:

The aim of this study is to recognize family caregiver's adjustment for their children with hearing impairment. The research questions: 1 ) is there a relation between family caregiver's adjustments about children with hearing impairment and their knowledge? 2) Is there a relation between family caregiver's adjustments and their practice? 3) Is there a relation between family's caregiver's knowledge and their practice?

\section{Subjects and Methods}

Research design: a descriptive analytical design was utilized to achieve the aim of the current study.

Study Setting: The study was conducted at Hearing and Speech Institute at Embaba district, under supervision of General organization of teaching hospitals and institutes, the role of the institute is diagnosis and rehabilitation of cases with hearing and communication problems.

Sample: convenient sampling was used sixty patients $(n=60)$, who had the willingness to be included in this study and met the inclusion criteria: Child under 5 years old, Child who diagnosed with hearing impairment, Free from any physical or mental problems, Both sexes were represented.

Tools of Data Collection: questionnaire includes fourth parts:

Part (I) Socio-demographic characteristics for family caregiver, this part assess: "Age, sex, degree of kinship, educational level".

Part (II) Family caregivers' knowledge interviewing questionnaire related hearing impairment, this part assess family caregivers' knowledge, and it consist of (10) questions related to definition, factors that cause hearing impairment, signs and symptoms, kind of treatment, treatment stages, follow-up system, and when to stop follow-up.

Scoring system of family caregivers' knowledge questionnaire

Studied sample was asked and recorded their responses on the family caregivers' knowledge questionnaire items as the correct answer was scored "1", and incorrect "zero". For each area of knowledge, was considered correct if the percent score was $50 \%$ or more and incorrect if less than $50 \%$.

Part (III) Family caregivers' reported practices questionnaire related to child hearing impairment, which consists of (3) questions as daily medical care to medical hearing aids, which includes 9 items, a cochlear implant care which includes 6 items, and Role in drug administration which includes 11 items.

\section{Scoring system of family caregivers' reported practices questionnaire}

Family caregiver's were asked and recorded their responses on family caregivers' reported practices questionnaire, a scoring system for each of practice items done correctly was scored "1", and not done "zero". For each area of practice, was considered done correctly if the percent score was $60 \%$ or more and not done if less than $60 \%$.

Part (IV) An adjustment scale to assess family caregivers' adjustment toward caring of the children with hearing impairment, this tool was adopted and modified from (Grant \& Rivera, 2001). 


$\begin{array}{llr}\begin{array}{c}\text { Scoring } \\ \text { caregivers' } \\ \text { questionnaire }\end{array} & \begin{array}{c}\text { system of } \\ \text { adjustment }\end{array} & \begin{array}{r}\text { family } \\ \text { scale }\end{array} \\ & & \end{array}$

Family caregiver's were asked and recorded their responses on family caregivers' adjustment scale questionnaire; this scale ranges from (2) always, (1) sometimes, too (0) never. Scoring system of adjustment scale classified as: Mal adjustment (0-14) scores, Moderate adjustment (15-22) scores, Adjustment (2330) scores.

Pilot Study: A pilot study was done on $10 \%$ from study sample and was carried out to assure content of the tool through five expertise from community health nursing, pediatric medicine. Some changes were done accordingly. Those who shared in the pilot study were excluded from the study sample.

Fieldwork: To carry out the study, the formal approval was obtained from Faculty of Nursing, Ain-Shams University. An official permission was obtained to the head of the Hearing and Speech Institute. Moreover, the investigator allocated 3 days per week for data collection in the previously mentioned setting, explained the purpose of the study and obtaining patients consent to participate were done firstly. In case of acceptance, investigator was clarified the questionnaire form, elements, questions for each study subjects as an individual, then record their responses, data collection was fulfilled during 3 months starting from August 15- 2015 to November 15-2015. The patients were assured that information collected would be treated confidentially, and it would be used only for the purpose of the research.

\section{Ethical considerations:}

The participants' informed consents were secured after explaining to them the aim of the study and its procedures. They informed about their rights to refuse or withdraw at any time without penalty, as well as the confidentiality of any information, the study maneuvers could not cause any harm to participants.

Statistical design: Data collected from the studied sample was revised, coded and entered using computerized data entry. The statistical analysis was fulfilled using the statistical package for social sciences (SPSS) version 17. Data were presented using descriptive statistics in the form of: 1) Quantitative variables are described by the Mean Standard Deviation (SD), the Range (Maximum - Minimum). 2) Qualitative categorical variables are described by proportions and Percentages. 
Results

Table (1): Distribution of family caregiver according to their socio-demographic characteristics $(n=60)$

\begin{tabular}{|c|c|c|}
\hline$\%$ & No & Socio-demographic Characteristic \\
\hline \multicolumn{3}{|c|}{ Age (Years) } \\
\hline $5.0 \%$ & 3 & $<25$ \\
\hline $35.0 \%$ & 21 & $25>30$ \\
\hline $35.0 \%$ & 21 & $30>35$ \\
\hline $20.0 \%$ & 12 & $35>40$ \\
\hline $5.0 \%$ & 3 & $>40$ \\
\hline \multicolumn{3}{|c|}{ Mean $\pm \mathrm{SD}=30.77 \pm 4.99$} \\
\hline \multicolumn{3}{|l|}{ Sex } \\
\hline $18.3 \%$ & 11 & Male \\
\hline $81.7 \%$ & 49 & Female \\
\hline \multicolumn{3}{|c|}{ The degree of kinship } \\
\hline $16.7 \%$ & 10 & Father \\
\hline $83.3 \%$ & 50 & Mother \\
\hline \multicolumn{3}{|c|}{ Educational level: } \\
\hline $23.3 \%$ & 14 & Illiterate \\
\hline $5.0 \%$ & 3 & Primary \\
\hline $43.3 \%$ & 26 & Secondary \\
\hline $28.3 \%$ & 17 & University \\
\hline
\end{tabular}

Table (1): showed that (70\%) of caregiver their aged from 25 to 35 years old, $(81.7 \%)$ were female, $(83.3 \%)$ were mothers. 
Figure (1): Distribution of family caregivers' according to total score level of their knowledge $(\mathrm{n}=60)$.

\title{
Correct Knowledge Level
}

\author{
Correct Knowledge Level
}

$98.30 \%$

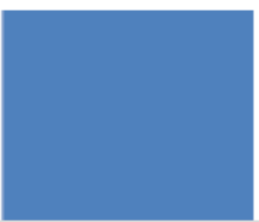

Correct
$1.70 \%$

\section{Incorrect}

Figure (1) showed that most of family caregivers (98.3\%) have acceptable score level of knowledge.

Figure (2): Distribution of family caregivers' related to their total practices

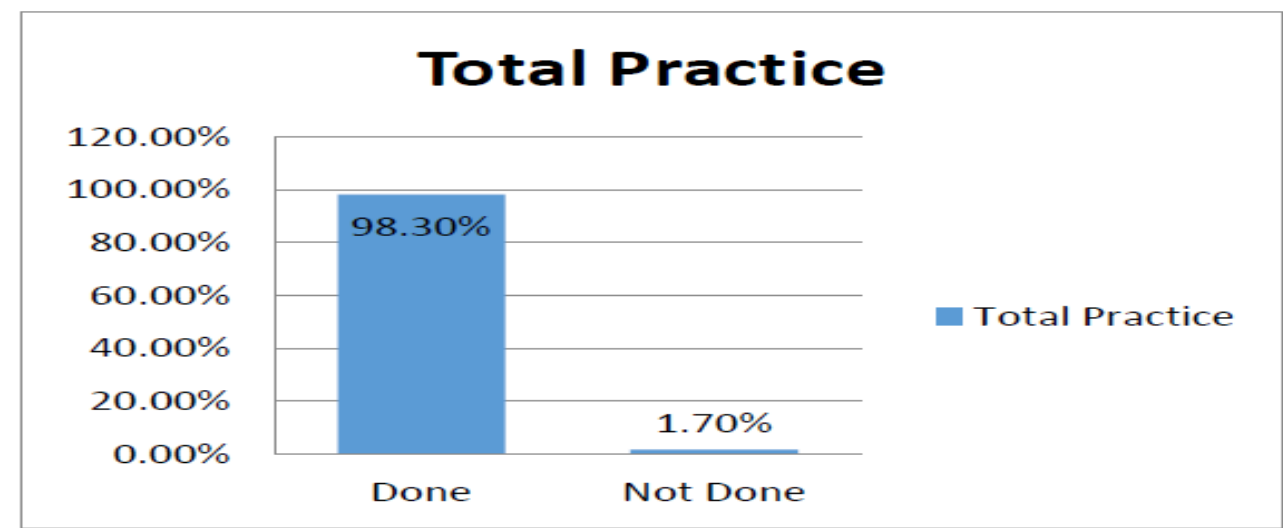

Figure (2) showed that most of practices (98.3\%) have done. 
Figure (3) Distribution of family caregivers' total adjustment level according to their children caring $(n=60)$

\section{Adjustment level}

\section{Total adjustment level}

$98.30 \%$

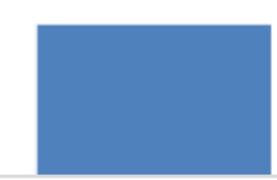

$1.70 \%$

\section{High adjustment level}

Low adjustment level

Figure (3) showed that most of caregivers (98.3\%) have high adjustment.

Table (2): Correlation between knowledge and practice, knowledge and adjustment, practice and adjustment

\begin{tabular}{|c|c|c|c|l|}
\hline \multicolumn{2}{|c|}{ Adjustment } & \multicolumn{2}{c|}{ Practices } & \multirow{2}{*}{ Variables } \\
\hline P value & $\begin{array}{c}\text { Pearson Correlation } \\
\text { Coefficient }\end{array}$ & P value & $\begin{array}{c}\text { Pearson } \\
\text { Correlation } \\
\text { Coefficient }\end{array}$ & \\
\hline .171 & .179 & .049 & $-.256^{*}$ & Knowledge \\
\hline .991 & -.001 & & & Practices \\
\hline
\end{tabular}

\section{Discussion}

The finding of the existing study will present and discus according to the following:

Regarding the socio-demographic characteristics for family caregivers, the current study finding shows that highest percentages of caregivers' age are between 25 to 35 years old, with Mean \pm $\mathrm{SD}=30.77 \pm 4.99$, the majority of them are female, This finding is consistent with the previous study at Department of School Counseling and Special Education, Tel Aviv University, Israel, which reporting that, mothers are considerably more involved than fathers in child's intervention, also, they are being more interest and attendance in the child's follow-up (Zaidman-Zait et al., 2017). This fact is reflecting that mothers are considered the main caregivers to children with hearing impairment. Moreover, the third quarter of the study sample did not work. Lastly, about third quarters of them, their number of family members ranged from four to five members.

Generally, the total score level of family caregivers' knowledge, revealed that the majority of family caregivers have acceptable score level of knowledge. this finding similar with a study in Manipal University, at a Department of Speech and Hearing, which assessed family caregivers' 
knowledge and attitude towards hearing loss in newborns, data revealed that the family caregivers showed positive knowledge towards hearing impairment, as screening , involvement options, follow up and adherence to medication Ravi et al. (2016)

Previous study for Fitzpatrick (2010), which was done At the Children's Hospital of Eastern Ontario, the University of Ottawa, in Canada, the findings were confirmed on infant hearing screening including parents' perspectives of benefits and needs. This framework was refined on the outcomes from the families' perspective and highlights factors as parent support, knowledge and coordinated services. Also similar with Hardonk et al. (2011) who did a qualitative analysis in Flanders, Belgium, which stressed the importance of paternal perspective concerning the use of their experiences related to screening and rehabilitation care for children with congenital deafness.

Relating to family caregivers' practices toward the daily medical care to Hearing aids, the highest percentages of family caregivers were represented that keep speakers within its own enclosure and remove the batteries before the medical hearing aid in box mode. The present study finding contrasts with prior cross-sectional survey was done from 43 states by Larsen et al. (2012) who assessed the early hearing detection and intervention, from parent experiences of children with hearing loss from 2 months of age to 11 months, results revealed that around half of the parents were receiving information about hearing aids care and its application.

Related the caregivers practice toward health needs of their children with a cochlear implant, the highest percentages of family caregivers were represented proper implant cochlear care, as develop a protective hat for the head while riding a bike or wheels latch or during soccer practice games and avoid an open shot in the head. On the same line, prior study for Schoepflin et al. (2015) who discussed case studies for parental restriction of children's access to cochlear implants, the article reports highlighted on the parental behavioral management of the implanted child included withholding the cochlear implant or activities associated with it as a disciplinary measure or as a means of preventing device loss or damage. The need for parental counseling by health care and educational professionals as to the importance of a child's connection to the hearing world all day long through the implant for optimal speech, language, academic, and psychosocial development is emphasized. From an investigator point of view, assess the family caregivers' practices toward the daily medical care to Hearing aids or cochlear implants, emphasized the importance of seeking practical support from a health professional for family caregivers to guarantee the acceptable competency level of care.

Concerning the family caregivers' adjustment according to their children caring, majority of family caregivers have high adjustment level, by trying so hard to prevent other things from a collision with their effort to take care of their child, they do their best for their child to overcome the disease and accept reality and satisfaction with it. This present results are dissimilar with Zaidman-Zait et al. (2015). The finding revealed that moderate level of parenting coping resources in the context of general self- and specific self-efficacy; in form of parents feel, they retain the knowledge and ability to improve their children's speech and language. 
In addition, the present study results are consistent with Jamieson et al. (2011), and Fellinger et al. (2012) who had diverse views on their results, both are measured the family coping and adjustment by some concerns of parents of deaf and hard-of-hearing children who have additional special needs. Their finding proves that, there was a range of special needs, as emotional, social, cognitive, and sensory. The experience of obtaining a definitive diagnosis itself was in itself challenging, as the hearing loss sometimes masked or blurred the other condition.

Regarding, the correlation between knowledge and practice, knowledge and adjustment, practice, and adjustment table (2) there is a positive nonsignificant correlation between family caregiver's knowledge and adjustment, there is almost no correlation between practice and adjustment. In addition, there is a negative weak significant correlation between family caregiver's knowledge and their practice. This result was contradicted by a study done by $\mathbf{E l}$ Guindi et al. (2011), who study coping patterns of mothers of children with epilepsy, the study results revealed that there was a statistically significant positive correlation between problems focuses coping with mother knowledge and practice.

\section{Conclusion:}

The study included that there was a negative significant correlation between knowledge and practice, there was positive non-significant correlation between knowledge and adjustment, and there was almost no correlation between practice and adjustment.

\section{Recommendation:}

The current study recommended that providing health education for family caregivers through strengthen immunization programs to prevent hearing impairment, which is a complication of infectious diseases, such as congenital rubella, meningitis, mumps, and measles. Continuous supervision of maternal and neonatal care by the Ministry of Health and Population. Moreover, Periodic Hearing Screening for Early Identification should be done for children before 6 months of age.

\section{References}

ASHA. (2016). American SpeechLanguage-Hearing Association. Scope of practice in speech-language pathology.

El Guindi, F. K., Guriguis, S., \& Moselhy, M. M. (2011). Coping patterns of mothers of children with epilepsy. Faculty of Nursing, Ain Shams University. (Ain shams university library, unpublished thesis).

Fellinger, J., Holzinger, D., \& Pollard, R. (2012). Mental health of deaf people. The Lancet, 379(9820), 1037-1044.

Fitzpatrick, E. (2010). A Framework for Research and Practice in Infant Hearing Cadre de travail pour la recherche et la pratique concernant les troubles de l'audition chez les enfants. Revue canadienne d'orthophonie et d'audiologie-Vol, 34(1).

Frances A. Maurer, Claudia M. Smith. (2013). Community/Public Health Nursing Practice: Health for Families and Populations. Elsevier Health Sciences. P. 712.

Grant, M. and Rivera, L. (2001). Quality of life, 2nd edmosby company, London, New York, p.p.4-10. 
Hardonk, S., Desnerck, G., Loots, G., Matthijs, L., Van Hove, G., Van Kerschaver, E.,... Louckx, F. (2011). From screening to care: A qualitative analysis of the parental experiences related to screening and (re) habilitation care for children with congenital deafness in Flanders, Belgium. The Volta Review, 111(3), 299.

Jamieson, J. R., Zaidman-Zait, A., \& Poon, B. (2011). Family support needs as perceived by parents of preadolescents and adolescents who are deaf or hard of hearing. Deafness $\&$ education international, 13(3), 110130.

Josephine Marriage, Tamsin Holland Brown, Naomi Austin. (2017). Hearing impairment in children. Elsevier. Available at http://www.paediatricsandchildhealthj ournal.co.uk/article/S17517222(17)30143-9/fulltext. Accessible at 23 July 2017.

Kim B., Heddwen B., Scott B., and Susan B. (2010). Ganong's Review of Medical Physiology. McGraw-Hill Companies; p.213.

Larsen, R., Muñoz, K., DesGeorges, J., Nelson, L., \& Kennedy, S. (2012). Early hearing detection and intervention: Parent experiences with the diagnostic hearing assessment. American Journal of Audiology, 21(1), 91-99.

Palo Alto Medical Foundation. (2015). Hearing Loss in Children. Available at

http://www.pamf.org/hearinghealth/fa cts/children.html.Accessed March 2015 at $8 \mathrm{pm}$.

Ravi, R., Gunjawate, D. R., Yerraguntla, K., Rajashekhar, B., \& Lewis, L. E.
(2016). Knowledge and attitude of parents/caregivers towards hearing loss and screening in newborns-a systematic review. International journal of audiology, 55(12), 715722.

Reddy, G. L. (2010). Hearing Impairment: An Educational Consideration. Discovery Publishing House, 11, 73-74.

Ronda C. Talley, Shirley S. Travis. (2013). Multidisciplinary Coordinated Caregiving: Research • Practice • Policy. Springer Science \& Business Media. P.5.

Schoepflin, J., Silverman, C. A., Linstrom, C. J., Gilston, N. S., \& DeRose, L. (2015). Parental restriction of children's access to cochlear implants: Case studies. Cochlear implants international, 16(2), 115-120.

World Health Organization, (2015). Community-Based Rehabilitation, Promoting ear and hearing care through CBR. Available at www.who.int/pbd/deafness/news/CB

REarHearingCare.pdf. Accessed March 2015 at 6pm.

Zaidman-Zait, A., Most, T., Tarrasch, R., Haddad-eid, E., \& Brand, D. (2015). The impact of childhood hearing loss on the family: Mothers' and fathers' stress and coping resources. Journal of deaf studies and deaf education, 21(1), 23-33.

Zaidman-Zait, A., Most, T., Tarrasch, R., \& Haddad, E. (2017). Mothers' and fathers' involvement in intervention programs for deaf and hard of hearing children. Disability and Rehabilitation, 1-9.

Zeng, F.-G., \& Djalilian, H. (2010). Hearing impairment. Plack CJ. The Oxford handbook of Auditory Science: Hearing. New York: Oxford, 325-348. 